\title{
CORRESPONDENCE
}

\section{PLANNED SERVICING OF AIRCRAFT}

In the discussion following that excellent lecture on "Problems Facing Civil Air Operations" by Mr. N. E. Rowe, published in the February 1948 JournaL, Mr. B. Kaiser paid the Royal Air Force a handsome compliment by referring to the Service's scientific approach to the economies of aircraft maintenance. He referred to the planned inspection system particularly, which is now common practice in the Royal Air Force and is fairly well known outside.

The planned inspection system, however, is only part of the story of the general rationalisation of flying and aircraft maintenance that has been taking place in the R.A.F. since the war. Planned inspection is part of the larger picture of Planned Servicing which also embraces component servicing; a system of repair by replacement, whereby all the removable bits and pieces of the aircraft are systematically serviced separately in component bays. Between these predictable activities of servicing, the manpower for unforeseen repair and rectification is shunted to avoid wasteful idleness of men and aircraft.

Much research has had to be done to find the right balance of men and aircraft to get this economy without compromising flying operations or flexibility of organisation. Meanwhile, much more thought and action than hitherto is being given to aircraft design for easier servicing - especially in the field. This economic requirement for military aircraft does not necessarily mean design for long life. It is more important to have reliability during the predictable life of aircraft, which are in war, expendable weapons. Production of military aircraft, therefore, has to be geared to the potential utilisation to be obtained from them. For example, it is well known that during the last war bomber aircraft rarely flew long enough to experience a major inspection. With this fact in view an aircraft designed to run trouble-free, for say 5,000 flying hours, would obviously be wasteful of productive effort. What we do require, however, is trouble-free running during a major cycle of flying. Our immediate aim is 1,000 hours.

Complementary to Planned Servicing is Planned Flying. The essence of Planned Flying is to effect greater utilisation of available aircraft: avoid irregular numbers of unserviceable aircraft due to flying; obtain the right ratios of air crew to aircraft; all in sympathy with the productive output of serviceable aircraft from the servicing organisation. In assessing all the factors the natural and imposed difficulties of the varying circumstances are taken into account, e.g. the weather or the available accommodation. In the latter respect there is no doubt that lack of proper technical accommodation is a handicap to real efficiency at the present time. Mr. Kaiser mentioned the difficulties of the conventional hangar to fit in with modern plans for economy. It may be of interest to the Society that I have submitted to the Air Ministry a completely new hangar design which has economy of overheads in view. The hangar is octagonal in shape, containing eight radially disposed aircraft bays around a central stalk of offices, stores, component bays, heating and power plants. The complete self-contained structure will be situated centrally in the technical site of an airfield. It is considered that the new design will considerably reduce the servicing and maintenance costs, including heat, light, power floor space, man hours, porterage, etc. For instance, each aircraft bay has its own hangar doors, therefore the heat lost and the man-hours lost by disturbance of work on the floor due to movement of aircraft in and out of the hangar is only incidental.

E. A. Harrop, O.B.E., Assoc. Fellow (Squadron Leader, R.A.F.). 